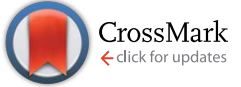

Cite this: RSC Adv., 2017, 7, 10545

Received 1st November 2016 Accepted 19th January 2017

DOI: 10.1039/c6ra26121c

rsc.li/rsc-advances

\section{Experimental investigation of upgrading of lignin- derived bio-oil component anisole catalyzed by carbon nanotube-supported molybdenum}

\author{
Behnam Rahzani, ${ }^{a}$ Majid Saidi, ${ }^{b}$ Hamid Reza Rahimpour, ${ }^{a}$ Bruce C. Gates ${ }^{c}$ \\ and Mohammad Reza Rahimpour ${ }^{\star a c}$
}

\begin{abstract}
Molybdenum supported on carbon nanotubes (CNTs) was synthesized and evaluated as a catalyst for the catalytic hydroprocessing of anisole. The CNTs and supported catalysts were characterized by $\mathrm{X}$-ray diffraction crystallography, scanning electron microscopy, energy-dispersive X-ray spectroscopy, and surface area/pore volume measurements. The anisole conversion products and selectivity-conversion data led to the identification of kinetically significant reaction routes, hydrodeoxygenation (HDO) and hydrogenolysis, accompanied by some alkylation, and transalkylation; for example, including anisole conversion to benzene by HDO and to phenol by hydrogenolysis, and formation of methyl-substituted phenols by transalkylation and alkylation. The activity and selectivity of the CNT-supported catalyst compare favorably with those of comparable catalysts on other supports, but the molybdenum in the carbon nanotubes limits the access of reactants to the catalytically active molybdenum species.
\end{abstract}

\section{Introduction}

The interest in applying renewable fuels to replace fossil fuels has expanded rapidly with increasing awareness of climate change influenced by $\mathrm{CO}_{2}$ emissions. ${ }^{1-4}$ Fast pyrolysis of biomass to form bio-oils is a potentially attractive approach to the direct conversion of lignocellulosic biomass, which is an abundant and carbon-neutral renewable energy resource..$^{5-8}$ The aldehydes, carboxylic acids, esters, and other oxygen-containing compounds in bio-oils hinder the utilization of this renewable energy source and motivate processes that remove these compounds. ${ }^{9-11}$ Technological deoxygenation processes such as catalytic hydrodeoxygenation are already practiced on a small scale. They lead to upgrading of bio-oils, increasing the heating value and the chemical and thermal stability of the fuels while decreasing the viscosity and corrosiveness. ${ }^{12-16}$ Such upgraded bio-oils, to varying degrees, already meet today's fuel specifications., ${ }^{\mathbf{1 7 - 1 9}}$

Much remains to be learned about the fundamentals of the processes for manufacturing bio-oils from biomass. The main goal of the work summarized here was to advance the understanding of the catalytic hydrodeoxygenation (HDO) of compounds in a large, underutilized class of biomass feedstocks, lignin. Specifically, our goals were to investigate the performance of a new class of catalyst for HDO of a compound

${ }^{a}$ Department of Chemical Engineering, Shiraz University, Shiraz 71345, Iran. E-mail: rahimpor@shirazu.ac.ir; mrahimpour@ucdavis.edu

${ }^{b}$ Faculty of Engineering, Shahrekord University, Shahrekord, Iran

${ }^{c}$ Department of Chemical Engineering, University of California, Davis, California 95616, USA representative of lignin-derived bio-oils, namely, anisole. This compound was chosen as a prototypical representative of lignin-derived compounds because it is aromatic and contains a methoxy group. Previous investigations of anisole HDO have been carried out with supported catalysts containing noble metals or phosphides, sulfides, or nitrides of molybdenum and other nonnoble metals; zeolites including HZSM-5 and faujasites have also been investigated as catalysts. ${ }^{\mathbf{1 , 1 5 , 2 0 - 2 8}}$ The most commonly investigated supports for HDO catalysts are porous metal oxides, typified by alumina. Here we report results characterizing molybdenum catalysts supported on a much less well investigated high-area support, carbon nanotubes (CNTs).

Interest in carbon nanotubes has grown rapidly recently as researchers have learned how to prepare them efficiently and recognized opportunities for applications to take advantage of their unique properties. ${ }^{29-34}$ A number of researchers have investigated CNTs as catalyst supports, interested by their inert surfaces, acid resistance, uniform pore size distributions, and resistance to coke deposition. ${ }^{29,32,33}$ CNTs are distinguished from other porous carbons (e.g., graphite and activated carbons) as catalyst supports by their high surface areas and superior electronic conductivities. ${ }^{29,31,33,34}$

Shang et al. ${ }^{29}$ investigated CNT-supported molybdenum catalysts (Mo/CNT) for hydrodesulphurization (HDS), and Soghrati et $a .^{35}$ tested NiCo/CNT catalysts for this class of reaction. The molybdenum-containing catalysts that have been used for HDS have also been investigated for HDO, but often the HDO catalysts are used in an unsulfided (i.e., oxide) form whereas the HDS catalysts become sulfided in operation. Prasomsri et $a l .{ }^{34}$ showed that molybdenum oxides are attractive 
choices for HDO, with catalysts in this class having relatively high activities for $\mathrm{C}-\mathrm{O}$ bond cleavage and high selectivities for HDO proceeding via such reactions. Ding et al. ${ }^{36}$ used Pd/CNT and $\mathrm{MoO}_{2} / \mathrm{CNT}$ catalysts for $\mathrm{HDO}$ of palmitic acid, observing that this reactant was converted to alkanes via $\mathrm{C}-\mathrm{O}$ bond cleavage. They concluded that the $\mathrm{MoO}_{2} / \mathrm{CNT}$ has both high activity and stability and is more attractive than $\mathrm{Pd} / \mathrm{CNT}$ for HDO of palmitic acid to form valuable products. In related work, Chen et al. ${ }^{37}$ examined a Ru/CNT catalyst for HDO of eugenol. Using a batch reactor, they found a high selectively to alkanes at more than $99 \%$ conversion of eugenol.

We now report an investigation of an unsulfided CNTsupported molybdenum catalyst for anisole conversion, providing more detailed, quantitative information than has been available and a preliminary basis for evaluating this class of catalyst for hydroprocessing of lignin-derived bio-oils.

\section{Experimental methods}

\subsection{Materials and catalyst}

Ammonium molybdate tetrahydrate, $\left(\mathrm{NH}_{4}\right) \mathrm{Mo}_{7} \mathrm{O}_{24} \cdot 4 \mathrm{H}_{2} \mathrm{O}$ (Merck), and multiwall carbon nanotubes (MWCNTs) with diameters of 50-60 nm (Notrino Co.) were used in the catalyst synthesis. MWCNT functionalization and treatment were carried out with sulfuric acid (98\%, Merck). Nitric acid (65\%, Merck), ethanol (98\%, Merck), and deionized water were used in various synthesis steps. Anisole (Sigma-Aldrich, 99\%) was used as a reactant in the catalytic reaction experiments. For verification of major components in the liquid products of the reaction, the analytical results were compared with those determined with authentic standards purchased from Sigma Aldrich.

\subsection{Catalyst preparation}

The molybdenum-supported-on-carbon-nanotube catalyst was synthesized by a two-step method involving support functionalization followed by impregnation with a molybdenum-containing precursor. The synthesis was carried out in a flow reactor. Multiwall carbon nanotubes (MWCNTs) with a diameter of 50-60 nm and a purity $>98 \%$ were used as a support for the catalyst referred to as Mo-CNT. The CNTs were pretreated and functionalized as follows: MWCNTs $(1 \mathrm{~g})$ were pretreated with $50 \mathrm{~mL}$ of nitric acid with sonication at $300 \mathrm{~K}$ for $1.5 \mathrm{~h}$ to remove impurities from the surface and enhance the anchoring of the catalyst. Then the CNTs were refluxed in a mixture of $65 \%$ nitric acid and $98 \%$ sulfuric acid with a volume ratio of 3 to 1 at $333 \mathrm{~K}$ overnight for functionalization and creation of defects on the MWCNT surfaces. The resultant functionalized multiwall carbon nanotubes (FMWCNT) were filtered and washed several times with deionized water and then washed again with ethanol and dried at $353 \mathrm{~K}$ for $14 \mathrm{~h}$. These FMWCNTs were used in the next step of the catalyst preparation. In the synthesis of each batch of catalyst, about $0.5 \mathrm{~g}$ of FMWCNTs was sonicated for $30 \mathrm{~min}$ in a precursor solution of $\left(\mathrm{NH}_{4}\right) \mathrm{Mo}_{7} \mathrm{O}_{24}-$ - $4 \mathrm{H}_{2} \mathrm{O}$, and then incorporation of the molybdenum by impregnation was performed by stirring the mixture for $4 \mathrm{~h}$ at $353 \mathrm{~K}$, followed by drying at $353 \mathrm{~K}$ for $5 \mathrm{~h}$ in air. Then, for calcination the catalyst was held in a stream of flowing $\mathrm{N}_{2}$ for $1.5 \mathrm{~h}$ as the temperature was increased at a rate of $5 \mathrm{~K} \mathrm{~min}^{-1}$ to reach $923 \mathrm{~K}$, and then, for catalyst reduction, the sample was exposed to a stream of $\mathrm{H}_{2}+\mathrm{N}_{2}$ with a molar ratio of $2 / 3$ at $923 \mathrm{~K}$. The resultant catalysts had target molybdenum loadings of 10,20 , and $30 \%$ by mass.

\subsection{Catalyst characterization}

Energy dispersive X-ray spectroscopy (EDS). All the catalyst samples after calcination were analyzed by EDS carried out with a Rontec EDS system, and the results are summarized in Table 1 and Fig. 1. Because the molybdenum was present in the form of oxide(s), oxygen was determined in the analyses; the results show that the molybdenum loadings were close to the values targeted in the syntheses $(9.7,18.4$, and $28.5 \mathrm{wt} \%$, respectively, for the samples intended to incorporate 10, 20\%, and $30 \mathrm{wt} \%$ molybdenum). Also as can be seen in Fig. 1e, oxygen peak has been disappeared in EDS image of reduced catalyst with molybdenum loading of $20 \mathrm{wt} \%$, because metal oxides converted to metal particles.

The Brunauer-Emmett-Teller (BET) surface area of each catalyst was measured with a PHSCHINA PHS-1020 apparatus, with $\mathrm{N}_{2}$ as the probe molecule. The X-ray diffraction (XRD) patterns of FMWCNTs and calcined fresh catalyst samples were obtained with a MPD 3000 X-ray diffractometer with a scan window of $0.02^{\circ}$. The average crystallite diameter was determined from the data with the Scherrer equation using the halfwidths of peaks. ${ }^{38}$ Catalyst topography was characterized by field emission scanning electron microscopy (FESEM), which was carried out with a Mira3 microscope. Samples of FMWCNTs with various catalyst loadings were prepared for FESEM by ultrasonic dispersion of the samples in ethanol, and then the suspensions were dropped onto aluminum foil. FESEM imaging was complemented by EDS. TEM analysis was performed with Zeiss-EM10C-100 kV microscope for $20 \%$ loading catalyst.

\subsection{Catalytic reaction experiments}

Catalytic reaction experiments with gas-phase reactants were carried out with a fixed-bed flow reactor at temperatures in the

Table 1 Catalyst specification

\begin{tabular}{|c|c|c|c|c|c|c|}
\hline Catalyst & $\begin{array}{l}\text { Targeted metal } \\
\text { content, wt } \%\end{array}$ & $\begin{array}{l}\text { Metal content measured } \\
\text { by EDS, wt } \%\end{array}$ & $\begin{array}{l}\text { BET surface } \\
\text { area, } \mathrm{m}^{2} \mathrm{~g}^{-1}\end{array}$ & $\begin{array}{l}\text { Pore volume, } \\
\mathrm{cm}^{3} \mathrm{~g}^{-1}\end{array}$ & $\begin{array}{l}\text { Average pore } \\
\text { diameter, } \mathrm{nm}\end{array}$ & $\begin{array}{l}\text { Average crystal size by } \\
\text { Scherrer equation, } \mathrm{nm}\end{array}$ \\
\hline FMWCNTs & - & - & 99.4 & 0.71 & 7.5 & - \\
\hline $10 \% \mathrm{Mo} / \mathrm{CNT}$ & 10 & 9.7 & 82.2 & - & - & 9.8 \\
\hline $20 \% \mathrm{Mo} / \mathrm{CNT}$ & 20 & 18.4 & 70.6 & 0.55 & 6.9 & 12.7 \\
\hline $30 \% \mathrm{Mo} / \mathrm{CNT}$ & 30 & 28.5 & 54.4 & - & - & 13.6 \\
\hline
\end{tabular}


a)

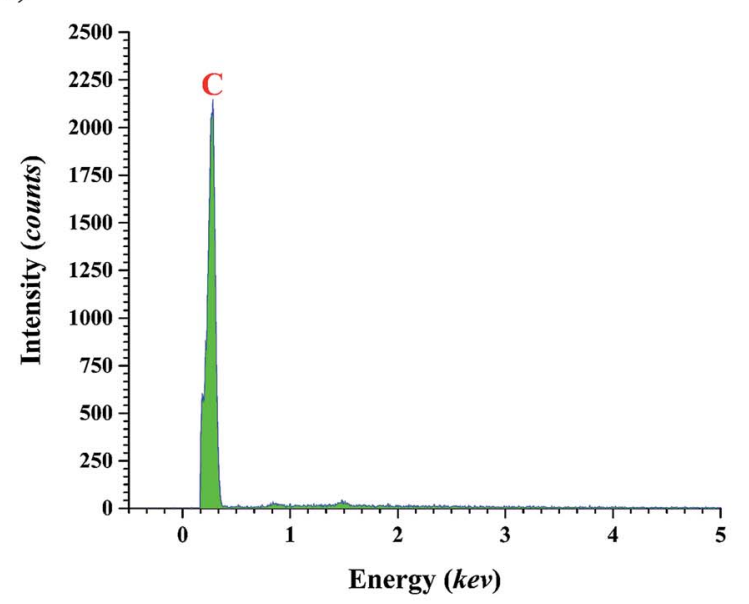

c)

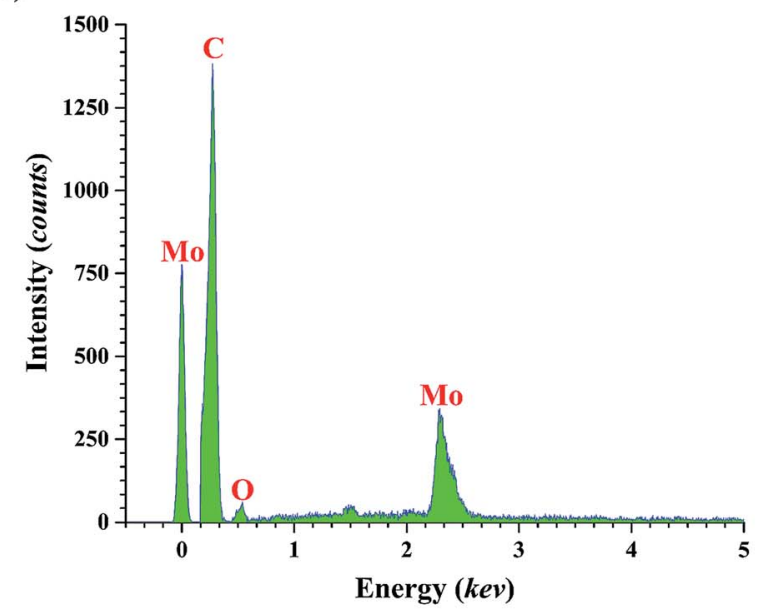

b)

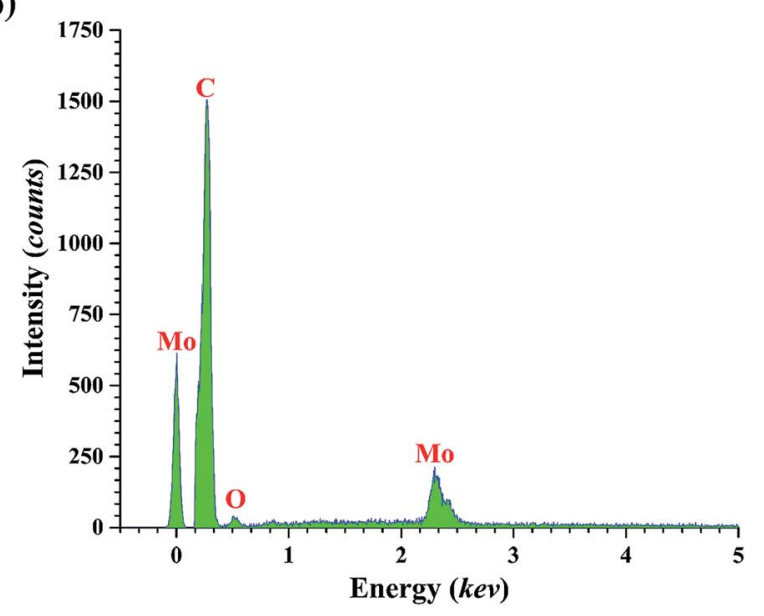

d)

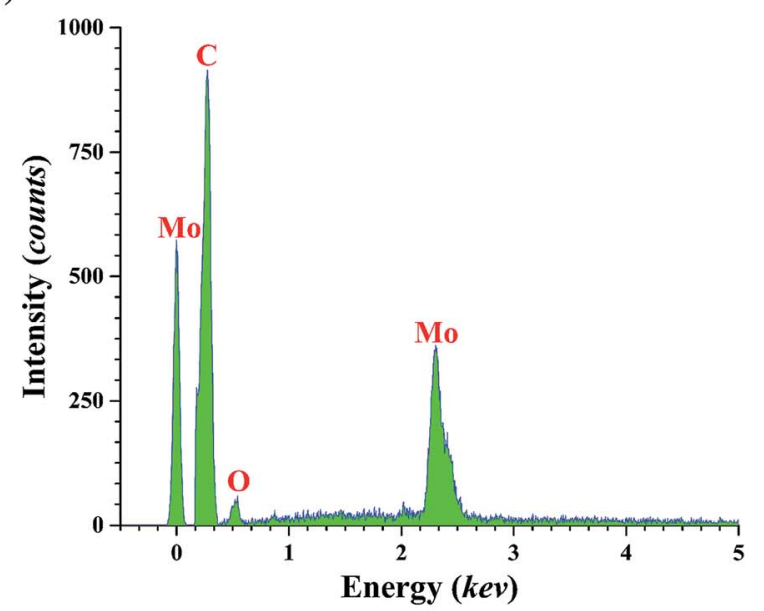

e)

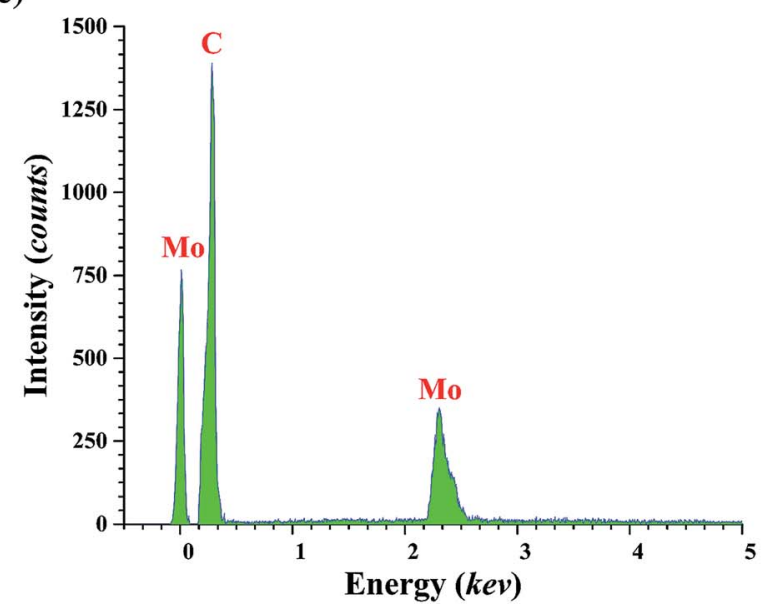

Fig. 1 The EDS patterns of FMWCNTs (a); calcined catalyst with loading of 10 wt\% molybdenum (b); 20 wt $\%$ molybdenum (c); and 30 wt\% molybdenum (d); and reduced catalyst with molybdenum loading of $20 \mathrm{wt} \%$ (e).

range of 573-673 $\mathrm{K}$ and a pressure of 8 bar. Anisole was fed at room temperature into the heated zone of the reactor system, flowing from an HPLC pump at a rate of $0.03 \mathrm{~mL} \mathrm{~min}{ }^{-1}$.
Preheated anisole was vaporized, and the vapor stream merged with the gas feed stream containing $\mathrm{N}_{2}$ as the carrier gas and $\mathrm{H}_{2}$ as a reactant. The $\mathrm{N}_{2}$ and $\mathrm{H}_{2}$ flow rates were each $20 \mathrm{~L}_{(\mathrm{NTP})} \mathrm{h}^{-1}$ in 
Table 2 Flow reactor system specifications and operating conditions

\section{Component of flow reactor system}

Reactor

\section{Carrier gas}

Reactant gas

Reactant liquid (vaporized in reactor)

Catalyst

\section{Property/operating conditions}

$316 \mathrm{~L}$ stainless steel; length $=305 \mathrm{~mm}$; inside diameter $=9 \mathrm{~mm}$; outside diameter $=14.5 \mathrm{~mm}$; operating temperature range, 623-723 $( \pm 1.5) \mathrm{K}$; operating pressure range, $8( \pm 0.1)$ bar

$\mathrm{N}_{2}$, flow rate, $20 \mathrm{~L}_{(\mathrm{NTP})} \mathrm{h}^{-1}$

$\mathrm{H}_{2}$, flow rate, $20 \mathrm{~L}_{(\mathrm{NTP})} \mathrm{h}^{-1}$

Anisole, flow rate range $0.03( \pm 1 \%) \mathrm{mL} \mathrm{min}^{-1}$ $\mathrm{Mo} / \mathrm{CNTs}$, mass $0.30 \mathrm{~g}$ a)

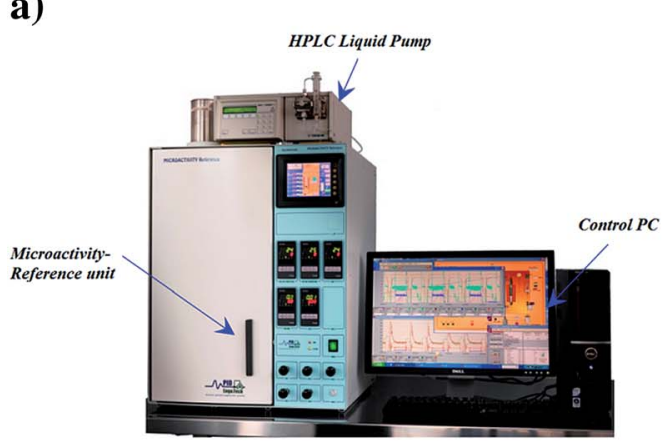

b)

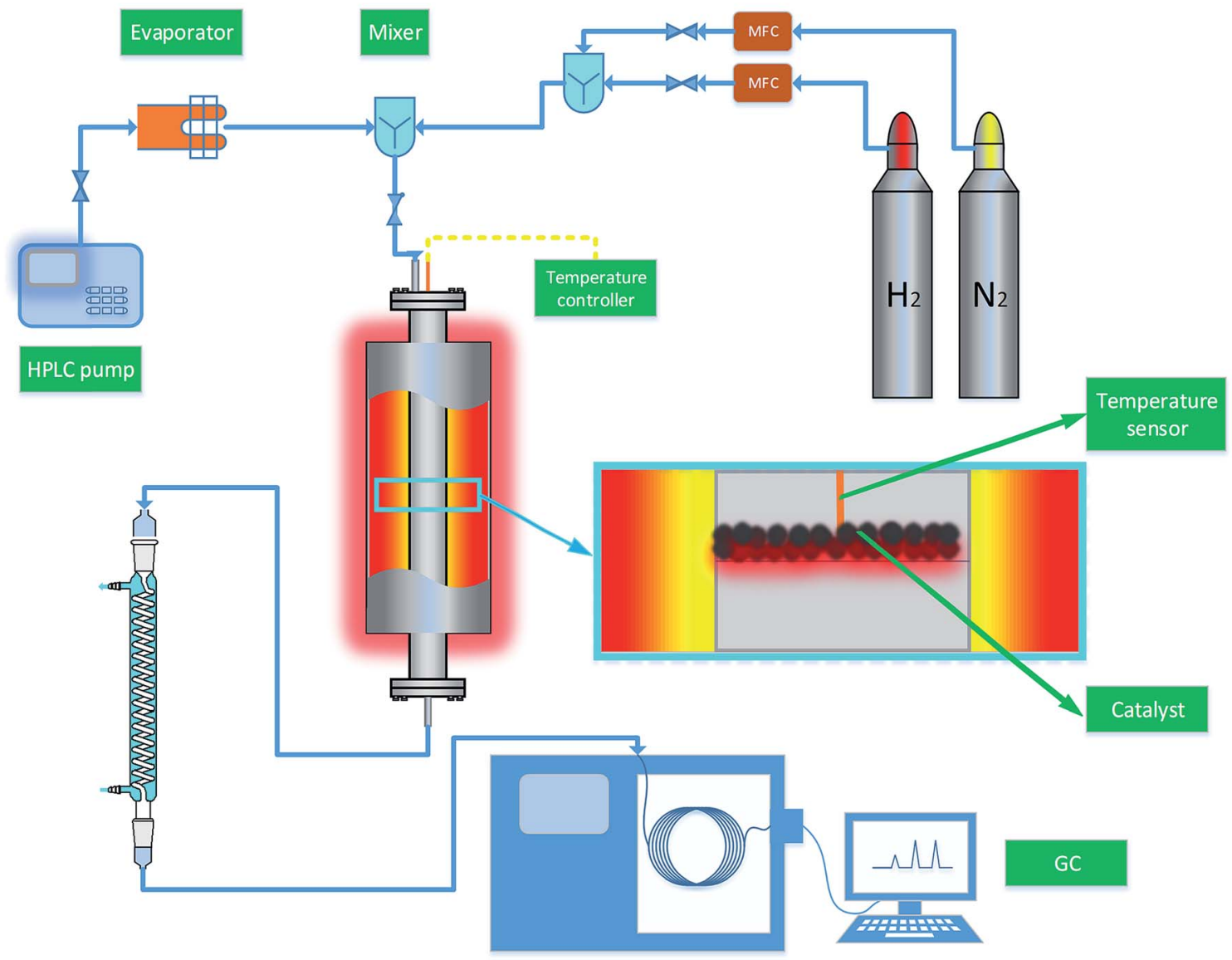

Fig. 2 (a) Fixed-bed tubular micro-flow reactor; (b) schematic flow diagram of reactor system. 


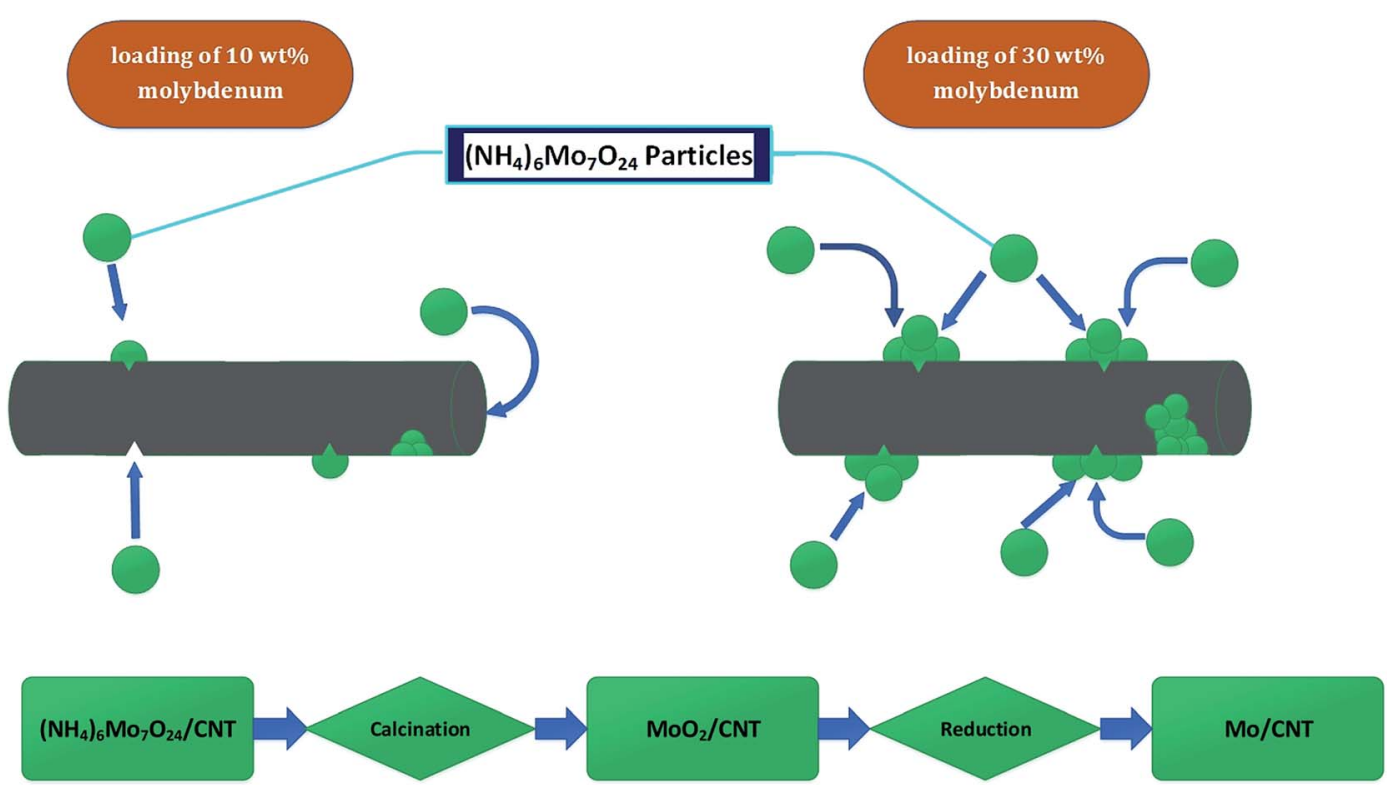

Fig. 3 Schematic, qualitative representation of distribution of catalyst particles in CNTs and flow chart of catalyst synthesis procedure.

all experiments. At the reactor outlet, the product stream flowed out of the heated zone to a condenser, which operated at 275$280 \mathrm{~K}$, and the accumulated liquid samples were collected for periodic analysis. Details of the reactor system are presented in Table 2 and Fig. 2. Fresh catalyst samples (about $0.3 \mathrm{~g}$ each) were used for each experiment, and each experiment was typically run for $3 \mathrm{~h}$ of continuous operation. The value of the weight hourly space velocity (WHSV) was 6 ( $\mathrm{g}$ of anisole per $\mathrm{g}$ of catalyst per h).

\subsection{Product analysis}

The outlet gas stream flowing from the condenser was analyzed online with a gas chromatograph (GC); the main components in the gas phase were $\mathrm{H}_{2}, \mathrm{~N}_{2}$, and product methane. Liquid product samples were analyzed with a Shimadzu QP 50/50 gas chromatograph-mass spectrometer (GC-MS); compounds were identified by matching mass spectra with those from a Willy library. GC peaks were verified by comparison with those of authentic standards. Liquid products were quantified with

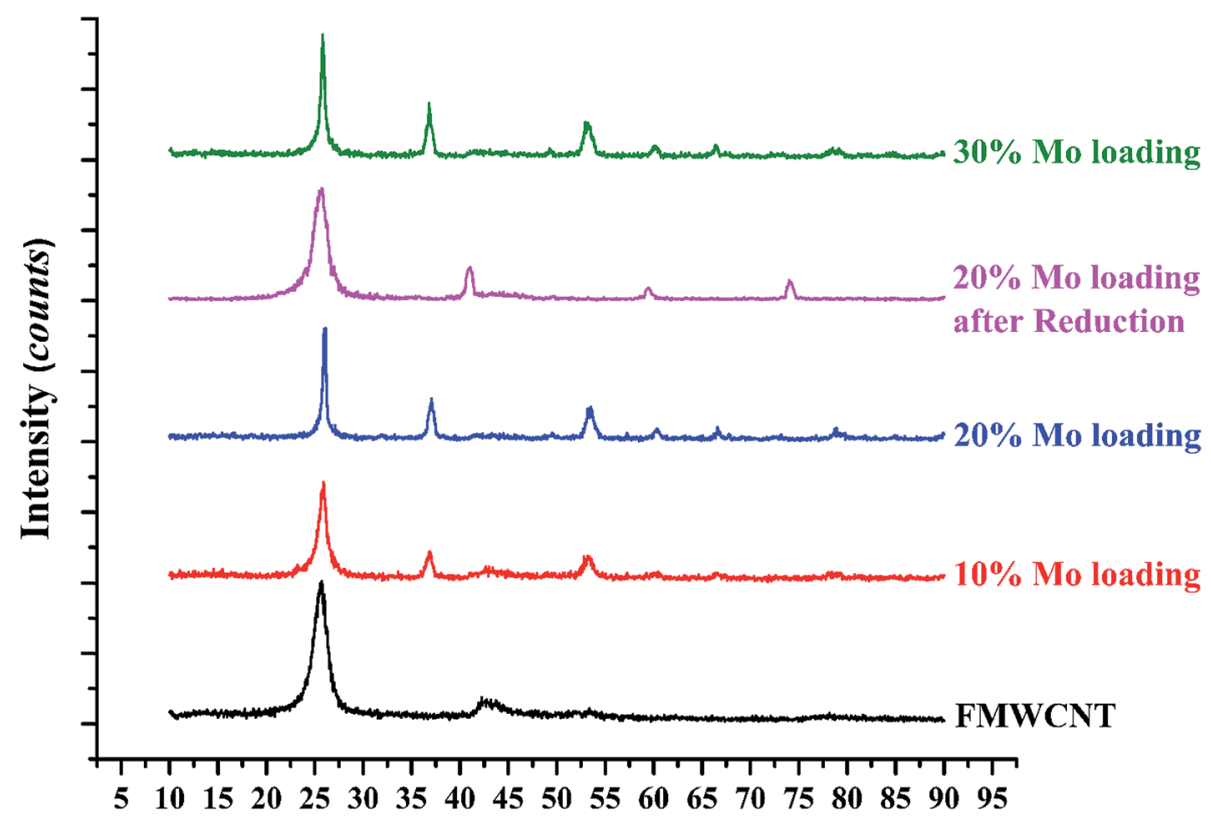

$2 \theta$ (degree)

Fig. 4 The XRD patterns of raw FMWCNTs and catalysts with various molybdenum loadings. 
a)

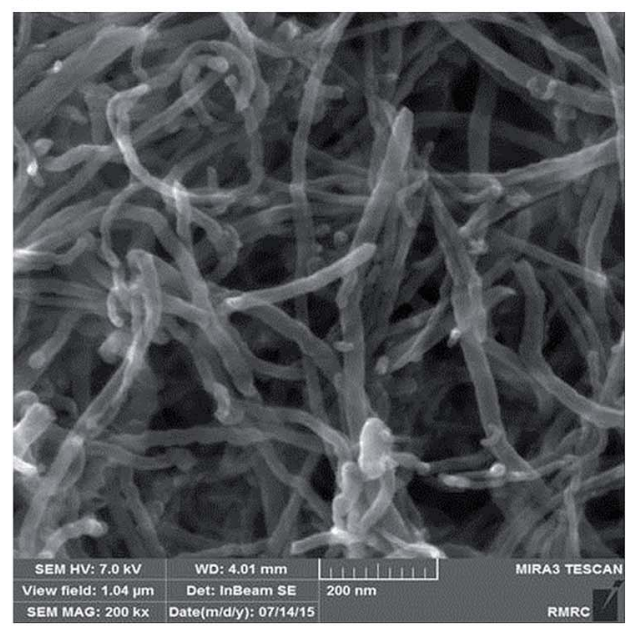

b)

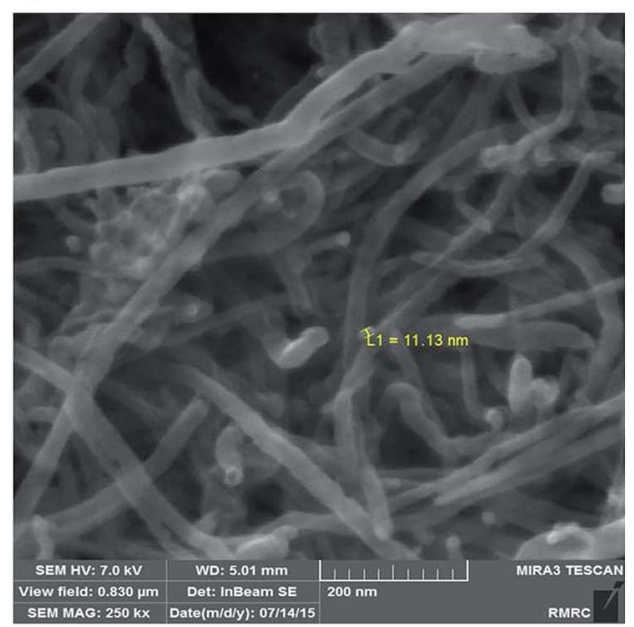

c)

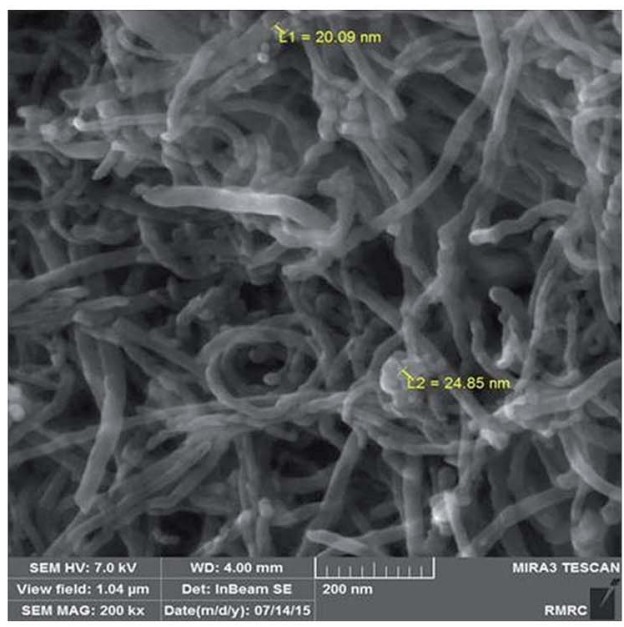

d)

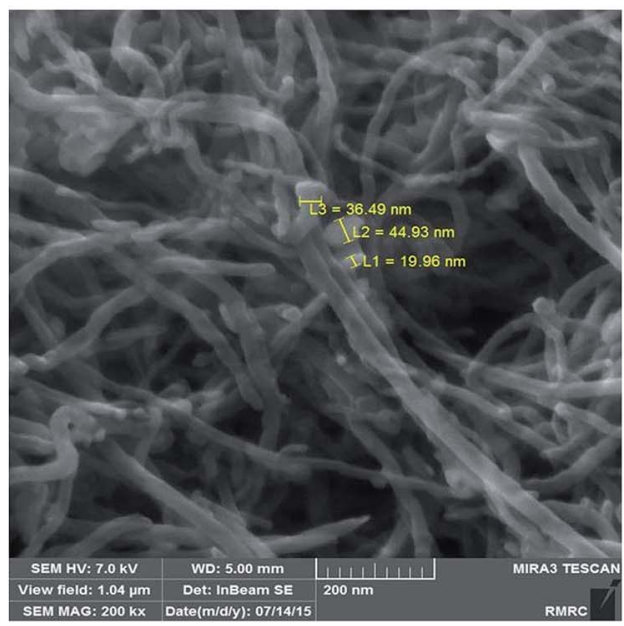

Fig. 5 FESEM images of catalysts. (a) FMWCNTs; catalyst with molybdenum loading of $10 \mathrm{wt} \%$ (b); $20 \mathrm{wt} \%$ (c); $30 \mathrm{wt} \%$ (d).

a Bruker 450 GC equipped with a flame ionization detector and an OPTIMA 5 Macherey-Nagel capillary column.

\section{Results}

\subsection{Catalyst characterization}

Surface areas and pore volumes. The BET data (Table 1) indicate that the catalyst surface area decreased with increasing molybdenum loading, suggesting that the molybdenum was to some degree present in agglomerated species on the CNT surface. As shown in Table 1, the BET surface area of the catalyst with $10 \mathrm{wt} \%$ molybdenum loading was significantly less than that of the FMWCNT sample itself, with the comparison being 82.2 vs. $99.4 \mathrm{~m}^{2} \mathrm{~g}^{-1}$. In agreement with these data, the results of Table 1, for example, show that the pore volume of the FMWCNT support was $0.71 \mathrm{~cm}^{3} \mathrm{~g}^{-1}$ and that of the supported catalyst containing $20 \mathrm{wt} \%$ molybdenum only $0.55 \mathrm{~cm}^{3} \mathrm{~g}^{-1}$. Thus, we infer that the reactant gas must have had limited access to the CNT interior surface and the catalytic species on it during catalysis. However, the data characterizing the samples

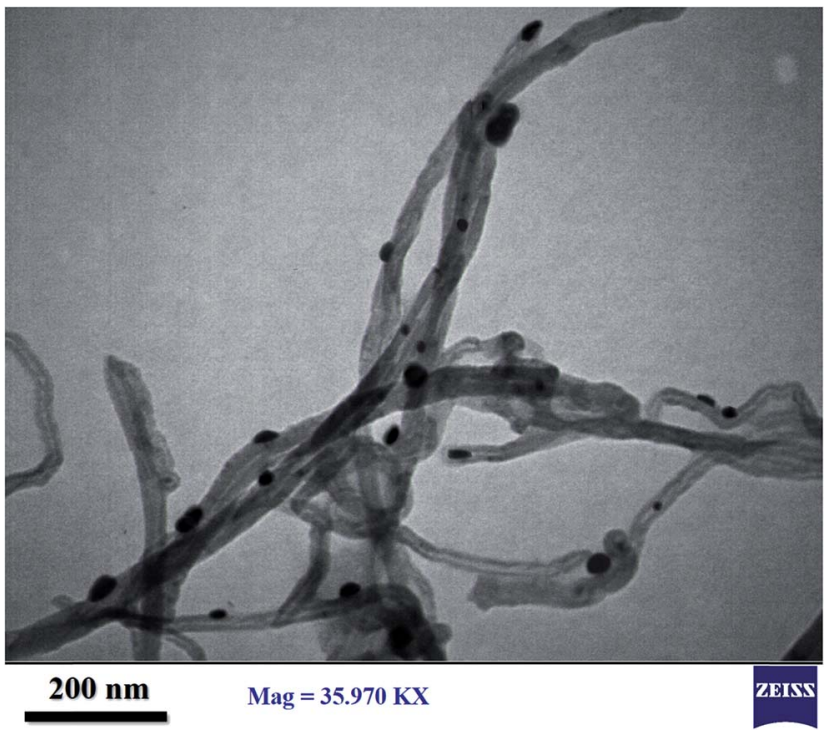

Fig. 6 TEM image of catalyst with molybdenum loading of $20 \mathrm{wt} \%$. 
Table 3 Overall mass balance closure data

\begin{tabular}{|c|c|c|c|c|c|c|c|}
\hline $\begin{array}{l}\text { Experiment } \\
\text { number }\end{array}$ & $\begin{array}{l}\text { Mass balance } \\
\text { closure, \% }\end{array}$ & $\begin{array}{l}\text { Time on } \\
\text { stream, min }\end{array}$ & $\begin{array}{l}\text { Liquid flow rate, } \\
\mathrm{mL} \min ^{-1}\end{array}$ & $\begin{array}{l}\text { Mass of liquid } \\
\text { fed, } g\end{array}$ & $\begin{array}{l}\text { Mass of liquid } \\
\text { collected from } \\
\text { condenser, g }\end{array}$ & $\begin{array}{l}\text { Mass of product } \\
\text { leaving condenser } \\
\text { as vapour, } \mathrm{g}\end{array}$ & $\begin{array}{l}\text { Approximate mass of } \\
\text { liquid remaining in } \\
\text { condenser, } g\end{array}$ \\
\hline 1 & 100 & 180 & 0.03 & 5.37 & 4.22 & 0.15 & 1 \\
\hline 2 & 101.6 & 180 & 0.03 & 5.37 & 4.31 & 0.15 & 1 \\
\hline 3 & 105.4 & 180 & 0.03 & 5.37 & 4.51 & 0.15 & 1 \\
\hline 4 & 98.1 & 180 & 0.03 & 5.37 & 4.12 & 0.15 & 1 \\
\hline 5 & 105 & 180 & 0.03 & 5.37 & 4.49 & 0.15 & 1 \\
\hline 6 & 99.4 & 180 & 0.03 & 5.37 & 4.19 & 0.15 & 1 \\
\hline 7 & 102.6 & 180 & 0.03 & 5.37 & 4.36 & 0.15 & 1 \\
\hline 8 & 98.5 & 180 & 0.03 & 5.37 & 4.14 & 0.15 & 1 \\
\hline 9 & 100.3 & 180 & 0.03 & 5.37 & 4.24 & 0.15 & 1 \\
\hline
\end{tabular}

with molybdenum loadings less than and greater than $20 \mathrm{wt} \%$ show that there was not a simple pattern of decreasing surface area with increasing molybdenum loading, and the results lead to the schematic representation of Fig. 3 suggesting that when $30 \mathrm{wt} \%$ molybdenum was present, multilayers formed and the molybdenum underwent agglomeration, so that in this sample with high loading the BET surface area was only $54.4 \mathrm{~m}^{2} \mathrm{~g}^{-1}$.

In summary, the results are consistent with the inference that molybdenum was present in particles on both the interior and exterior surfaces of the CNTs and to some degree blocked pores and access of reactants to the active sites during catalysis. Catalyst performance data summarized below are consistent with the inference.

$\mathrm{X}$-ray diffraction and complementary characterization data. Catalyst molybdenum contents (including the targeted values and those determined by experiment), surface areas, and average crystal sizes determined by XRD are reported in Table 1 along with results for FMWCNTs.

The XRD patterns of raw FMWCNTs and catalysts with various molybdenum loadings are shown in Fig. 4; the peak at $2 \theta=25.6^{\circ}$ representing the graphitic plane reflection in carbon nanotubes (002) is evident in the diffraction patterns of all the samples, as are broad peaks at $42.3^{\circ}$ representing a graphite plane $(100){ }^{39}$

The diffraction peaks at $37,53.1$, and $60.2^{\circ}$ are characteristic of $\mathrm{MoO}_{2}$. In related work, Shang et $a .^{29}$ reported that for Mo contents up of $8 \%$ after a calcination step, $\mathrm{MoO}_{2}$ particles formed as mentioned in EDS analysis after reduction Mo oxide converted to Mo, XRD analysis verify this phenomenon the peak of reduced catalyst shown in Fig. 4 , peak at $2 \theta=40.8^{\circ}, 59.5^{\circ}$ and $74^{\circ}$ are characteristic of molybdenum. The average crystallite sizes determined with the Scherrer equation (Table 1) show that the average crystallite size increased with increasing molybdenum loading, consistent with the results of the BET surface areas and, as shown in the next section, FESEM results.

FESEM and TEM data. FESEM analysis of FMWCNTs and catalysts with various molybdenum loadings are shown in Fig. 5. Data characterizing FWCNTs without molybdenum, having an average diameter of 50-60 nm, are shown in Fig. 5a. The results shown in Fig. 5b demonstrate the presence of small molybdenum-containing particles on the exterior surfaces of the CNTs when the molybdenum loading was $10 \mathrm{wt} \%$, and the results of Fig. 5c show a higher degree of agglomeration of these particles when the loading was $20 \mathrm{wt} \%$ molybdenum. This agglomeration is indicated by the greater diameter of the particles in the latter sample, 17-25 nm. And the image of Fig. $5 \mathrm{~d}$ shows that when the molybdenum loading was higher, $30 \mathrm{wt} \%$, the dispersion of the molybdenum-containing species was still lower. Fig. 6 indicated TEM image of reduced catalyst with molybdenum loading of $20 \mathrm{wt} \%$. The TEM analysis is carried out by Zeiss-EM10C-100 kV. As shown in Fig. 6, metals particle are clearly identified in TEM image.

In summary, these results are consistent with the surface area/pore volume data and support the inference of pore blocking and the pattern of decreasing molybdenum dispersion with increasing molybdenum content in the catalysts.

\subsection{Products of anisole conversion in the presence of $\mathbf{H}_{2}$}

The main products of anisole conversion catalyzed by the Mo/ CNT samples, identified by GC-MS, were benzene, phenol, 2methylphenol, 2,6-dimethylphenol, and 2,3,5,6-tetramethylphenol. Trace products that were detected only qualitatively were cyclohexane, toluene, $o$-xylene, $p$-xylene, and phenol derivatives such as isomers of methylphenol, dimethylphenol, trimethylphenol, and tetramethylphenol. The GC-MS analyses also demonstrated the formation of small amounts of methane, methanol, and water. Production of benzene associated with the formation of water and methanol confirms that HDO reactions occurred on the catalyst. The observation that phenol was the main product of the conversion shows that hydrogenolysis is a major class of reaction in the anisole conversion. The GCMS results also lead to the conclusion that alkylation/ transalkylation of phenol to give other phenol derivatives took place.

\subsection{Mass balance closures}

Anisole conversions in the catalytic reaction process were calculated on the basis of flow rates of liquid anisole to the reactor and the liquid condensate flowing from the external condenser, as well as the product gas flow rates (although the gas flow rates of anisole and the main products were almost negligible, as determined from the vapor pressures of these compounds at the condenser outlet temperature). Some 


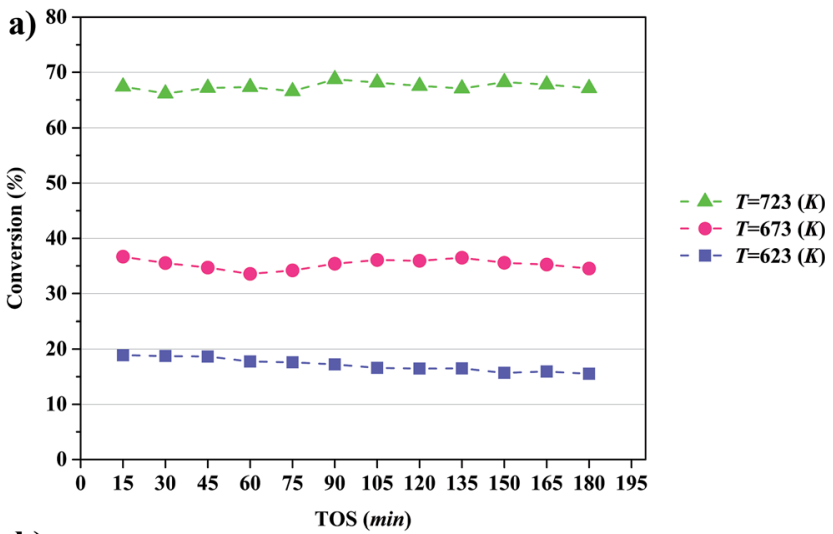

b)

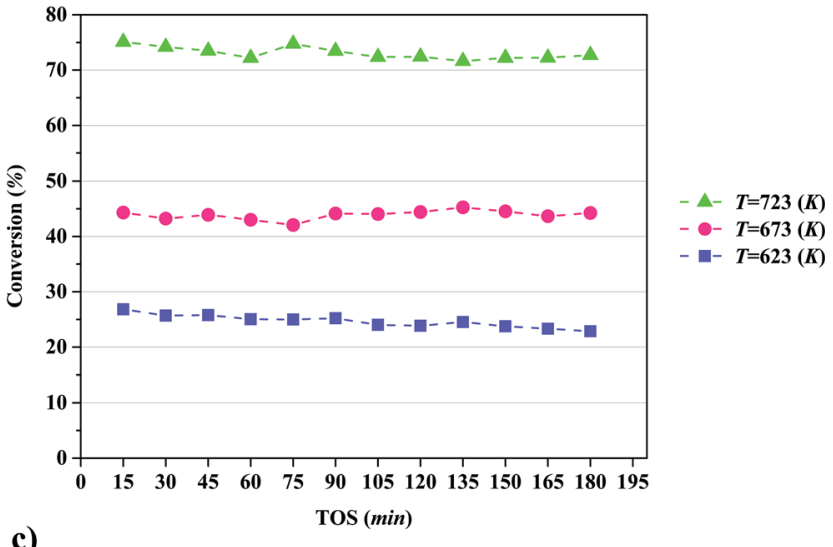

c)

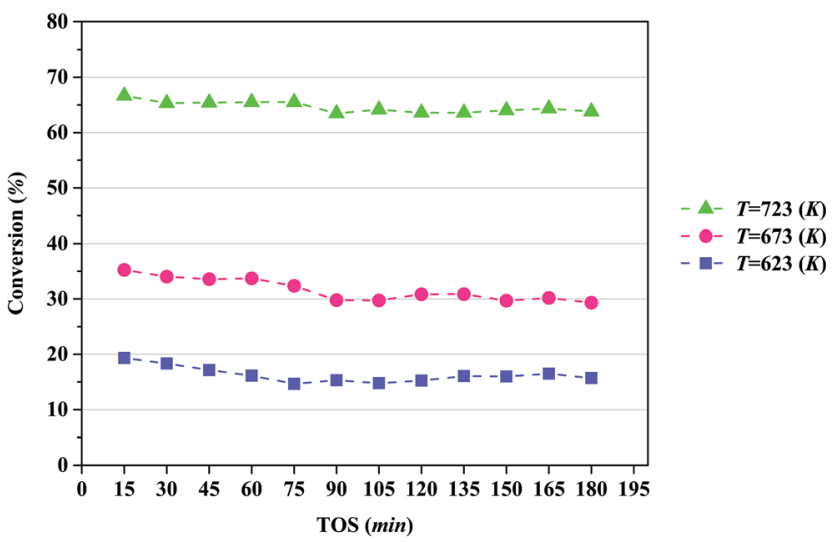

Fig. 7 Conversion of anisole catalyzed by Mo/CNT in the presence of $\mathrm{H}_{2}$ in a once-through flow reactor (TOS is time on stream) at the following approximate molybdenum loadings (wt\%): (a) 10; (b) 20; (c) 30.

products, such as methane, were present in the gas phase, and they were accounted for in the mass balance on the basis of the flow rates of the gas-phase products and calculations on the basis of the Antoine vapor pressure correlation for the various products. In the mass balance calculations, the mass flow rate of liquid anisole fed to the reactor in each operating period was determined from the liquid volumetric flow and the density of the anisole $\left(0.995 \mathrm{~g} \mathrm{~mL}^{-1}\right)$. Furthermore, because the condenser did not drain perfectly, the mass of the condenser and its contents was measured before and after sample collection to account for accumulation in the condenser. Thus, the mass of condensed liquid produced in each operating period of $15 \mathrm{~min}$ was measured as the sum of the mass of liquid collected from condenser and that accumulated in the condenser. The mass balance data shown in Table 3 confirm the reliability of the results, with mass balance closures being close to $100 \%$.

The catalytic reaction experiments were performed for $180 \mathrm{~min}$ of continuous operation, with product samples taken every $15 \mathrm{~min}$. Average conversions of anisole from these periods were used to determine the conversions under the various operating conditions.

\subsection{Conversion and selectivity as a function of time on stream}

The conversion of anisole catalyzed by Mo/CNTs as a function of time on stream (TOS) at various temperatures and molybdenum loadings is shown in Fig. 7, with the data representing $6 \mathrm{~h}$ experiments. It is evident that the catalyst performance changed only little during the course of each experiment, and we therefore represent the data as characteristic of initial catalyst performance.

As expected, the anisole conversion increased with increasing temperature. For example, data characterizing the catalyst incorporating $20 \mathrm{wt} \%$ molybdenum (Fig. 7b) show that a temperature increase from 623 to $673 \mathrm{~K}$ led to an increase in anisole conversion from about $25 \%$, on average, to about $45 \%$, on average. The data also show that increasing the catalyst molybdenum loading from 10 to $20 \mathrm{wt} \%$ at $723 \mathrm{~K}$ led to an increase in the anisole conversion from about 68 to about $75 \%$, on average, but that a further increase in the molybdenum loading to $30 \mathrm{wt} \%$ led to a decreased conversion.

Selectivities to the major products as a function of TOS at a temperature of $723 \mathrm{~K}$, a pressure of 8 bar, a WHSV of 6 ( $\mathrm{g}$ of anisole per $\mathrm{g}$ of catalyst per $\mathrm{h}$ ), with the catalyst containing and $20 \mathrm{wt} \%$ molybdenum, are summarized in Fig. 8. Again, the data indicate that the catalyst performance was essentially stable over the course of the $6 \mathrm{~h}$ experiments. The data show that the products formed with greatest selectivity were phenol and benzene; specifically, the selectivity for formation of phenol was found to be greater than that for formation of 2-methylphenol, 2,6-dimethylphenol, and 2,3,5,6-tetramethylphenol. Thus, we infer, as in earlier work with a different catalyst, ${ }^{\mathbf{1 8 , 2 1 , 2 2 , 4 0 , 4 1}}$ that major reaction routes are HDO, hydrogenolysis, alkylation, and transalkylation. Details of the reaction network are presented in the Discussion section.

\subsection{Effect of temperature and molybdenum loading on selectivity}

The effect of temperature on the selectivity to the formation of various products during anisole upgrading with catalysts having various molybdenum loadings is shown in Fig. 9-11. The data of Fig. 9 show that the selectivity to benzene as the product of the $\mathrm{HDO}$ reaction at $8 \mathrm{bar}, \mathrm{WHSV}=6$ ( $\mathrm{g}$ of anisole per $\mathrm{g}$ of catalyst per $\mathrm{h}$ ) with a catalyst containing $10 \mathrm{wt} \%$ molybdenum decreased from 60 to $10 \%$ as the temperature increased from 623 to $723 \mathrm{~K}$. Increasing the temperature enhanced the selectivity for formation of phenol, 2,6-dimethylphenol, and 2,3,5,6- 
a)

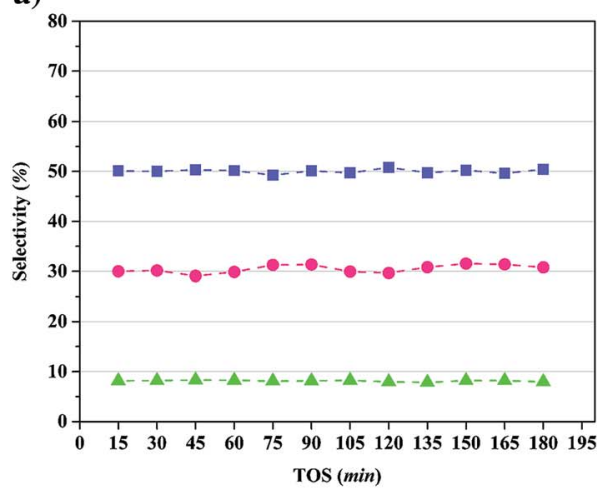

b)

Phenol

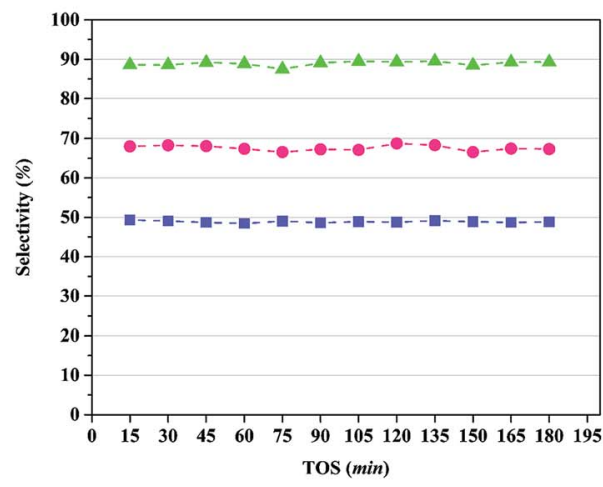

c)

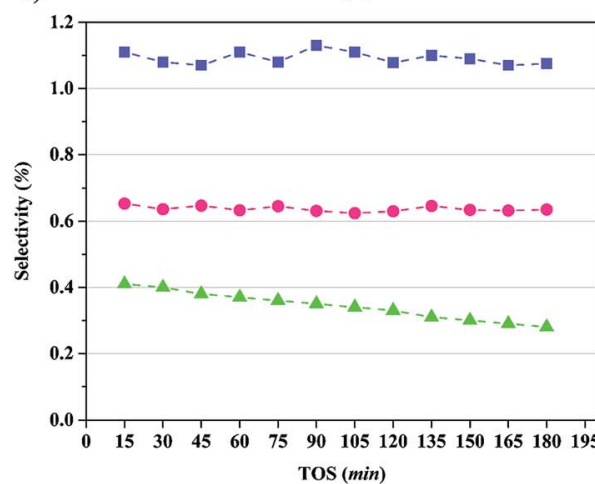

d)

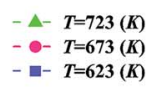

$\triangle-T=723(K)$

- $T=673(K)$

$\Delta=723(K)$

- $T=673(\pi)$

- $T=623(K)$

e)
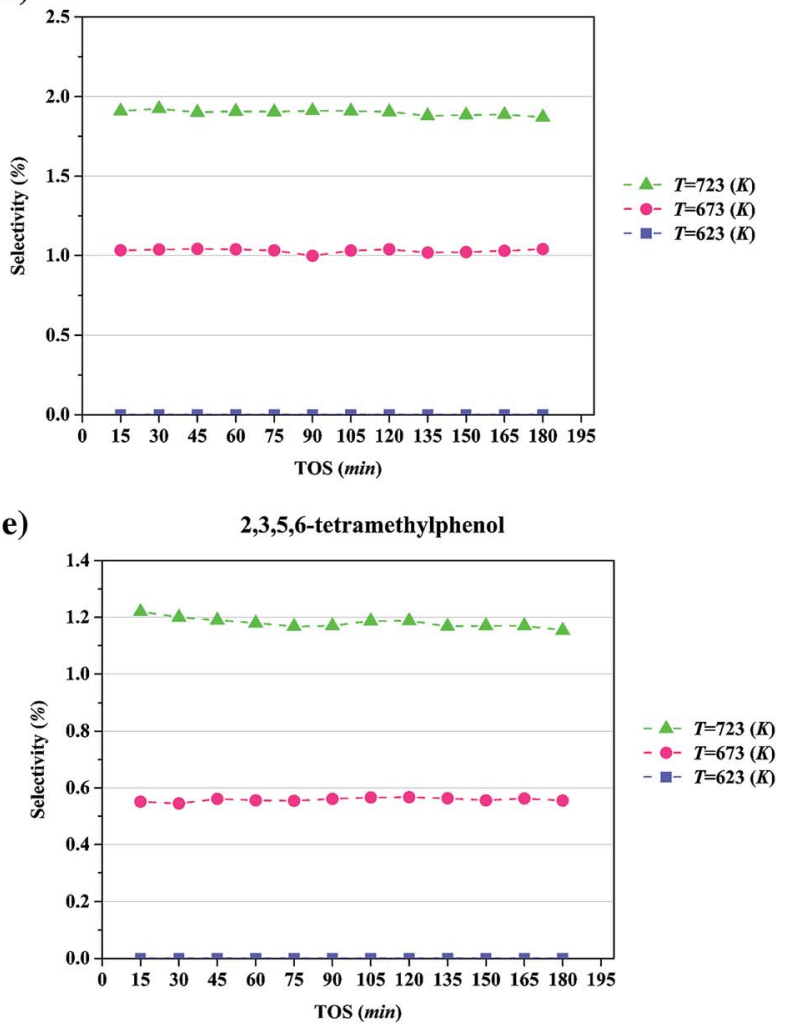

Fig. 8 Selectivities in anisole conversion to major products in a once-through flow reactor catalyzed by Mo/CNT at a pressure of 8 bar and WHSV = 6.0 (g of anisole per g of catalyst per h): (a), benzene; (b), phenol; (c), 2-methylphenol; (d), 2,6-dimethylphenol; and (e), 2,3,5,6tetramethylphenol.

tetramethylphenol, products of hydrogenolysis and alkylation reactions, but it decreased the selectivity for formation of 2methylphenol, a transalkylation product.

\section{Discussion}

The products observed in this work are similar to those observed in earlier hydroprocessing experiments with anisole as the reactant, but with catalysts different from ours. ${ }^{22,40}$ Thus, at least to a first approximation, we suggest that the reaction classes are the same as those inferred in the earlier work, specifically including direct bond-breaking of the $\mathrm{C}_{\text {aromatic }}-\mathrm{O}$ bond of anisole, leading to benzene and methanol. Another possible deoxygenation route involves demethylation via scission of the $\mathrm{C}_{\text {methyl }}-\mathrm{O}$ bond to give phenol, which may be followed by conversion of the phenol to benzene by hydrogenolysis of the $\mathrm{C}_{\text {aromatic }}-\mathrm{O}$ bond. Because the second route is kinetically dominant, we suggest that the scission of the $\mathrm{C}_{\text {methyl }}-\mathrm{O}$ bond is faster than the scission of the $\mathrm{C}_{\text {aromatic }}-\mathrm{O}$ bond. The selectivity data presented in Fig. 8a, in combination with the aforementioned literature, indicate that other kinetically significant reactions include hydrogenolysis of the aromatic carbonoxygen bond to form phenol as a main product, followed by phenol conversion to phenol derivatives via alkylation and transalkylation reactions. 


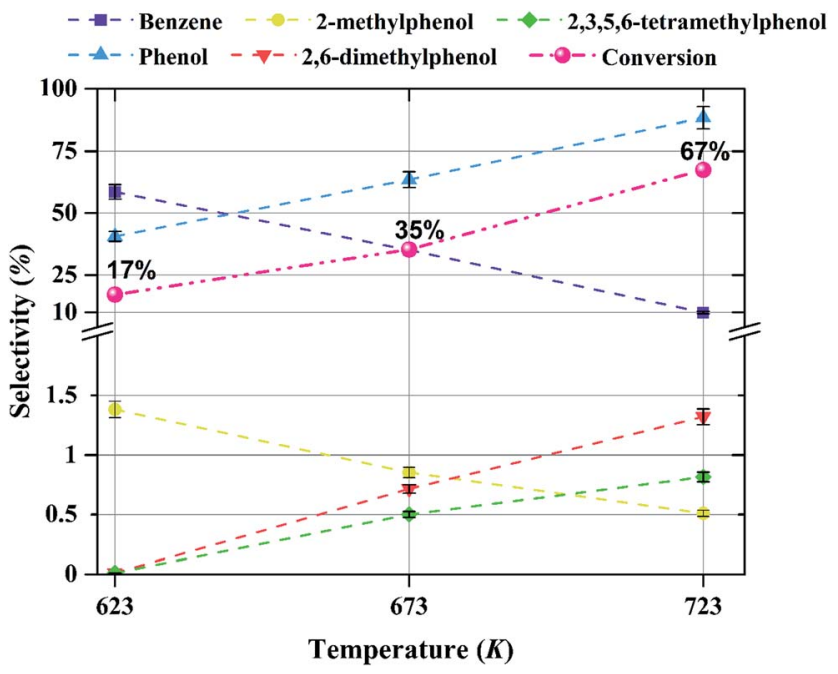

Fig. 9 Effect of temperature on selectivity for the formation of various products in anisole upgrading in the presence of $\mathrm{H}_{2}$ catalyzed by $\mathrm{Mo} /$ CNTs at 8 bar, with WHSV $=6.0$ ( $\mathrm{g}$ of anisole per $\mathrm{g}$ of catalyst per h); the catalyst molybdenum loading was $10 \mathrm{wt} \%$. The conversions are shown next to each point.

The data indicate that selectivity for oxygen removal is favored by operation at lower temperatures; the trends were observed for our catalysts with various molybdenum loadings (Fig. 10 and 11). The data also show that for the catalysts containing 10 and $20 \mathrm{wt} \%$ molybdenum, increasing the molybdenum loading leads to an increase in the hydrogenolysis selectivity more than the HDO selectivity. For example, at $623 \mathrm{~K}$, the selectivity to benzene decreases from approximately $60 \%$ to approximately $50 \%$ as the catalyst molybdenum content increases from 10 to $20 \mathrm{wt} \%$, whereas the selectivity to phenol increases from approximately $40 \%$ to approximately $50 \%$.

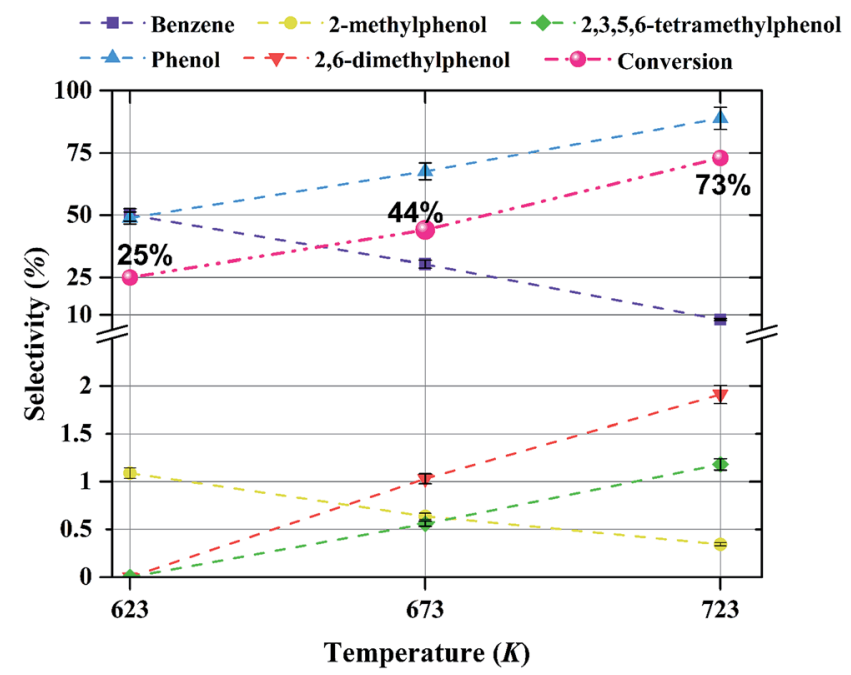

Fig. 10 Effect of temperature on selectivity for the formation of various products in anisole upgrading in the presence of $\mathrm{H}_{2}$ catalyzed by Mo/CNTs at 8 bar, with WHSV $=6.0$ ( $\mathrm{g}$ of anisole per $\mathrm{g}$ of catalyst per h); the catalyst molybdenum loading was $20 \mathrm{wt} \%$. The conversions are shown next to each point.
With bifunctional catalysts such as molybdenum supported on $\gamma-\mathrm{Al}_{2} \mathrm{O}_{3}$, some reactions, including alkylation, are catalyzed by the acidic support. But CNTs are more weakly acidic than oxides such as $\gamma-\mathrm{Al}_{2} \mathrm{O}_{3}$ and $\mathrm{TiO}_{2}$, and therefore the selectivity to phenol derivatives with CNT-supported molybdenum catalysts was expected to be less than was observed with these other supports. The observations bear out this expectation, and the oxygen removal is attributed largely to the role of the molybdenum-containing species activating $\mathrm{H}_{2}$ for

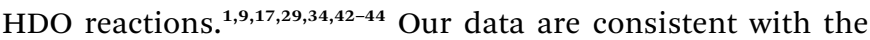
premise that the molybdenum species are active for both HDO and hydrogenolysis reactions, and we thus consider it likely that these species catalyze HDO to form benzene, which is kinetically a highly significant reaction under our conditions. On the basis of these inferences, we suggest a simplified, qualitative, and approximate reaction network for anisole hydroprocessing on Mo/CNTs, as shown in Fig. 12; we emphasize that the alkylation reactions are minor in comparison with the others shown.

To check whether the catalyst performance data were influenced by the rates of external mass transport, we varied the feed flow rate and catalyst mass with WHSV held constant at 6.0 ( $\mathrm{g}$ of anisole per $\mathrm{g}$ of catalyst per $\mathrm{h}$ ). As shown in Table 4 , the anisole conversions at constant WHSV and different catalyst masses were found to be approximately the same, consistent with the inference that external mass transfer did not influence the reaction rates.

The possible importance of mass transport limitations within the carbon nanotubes is, however, considered to be significant, and this point is developed below.

The physical characterization data show various degrees of dispersion of the molybdenum, depending strongly on the loading, and they indicate that particulate molybdenumcontaining species are substantially present within the CNTs

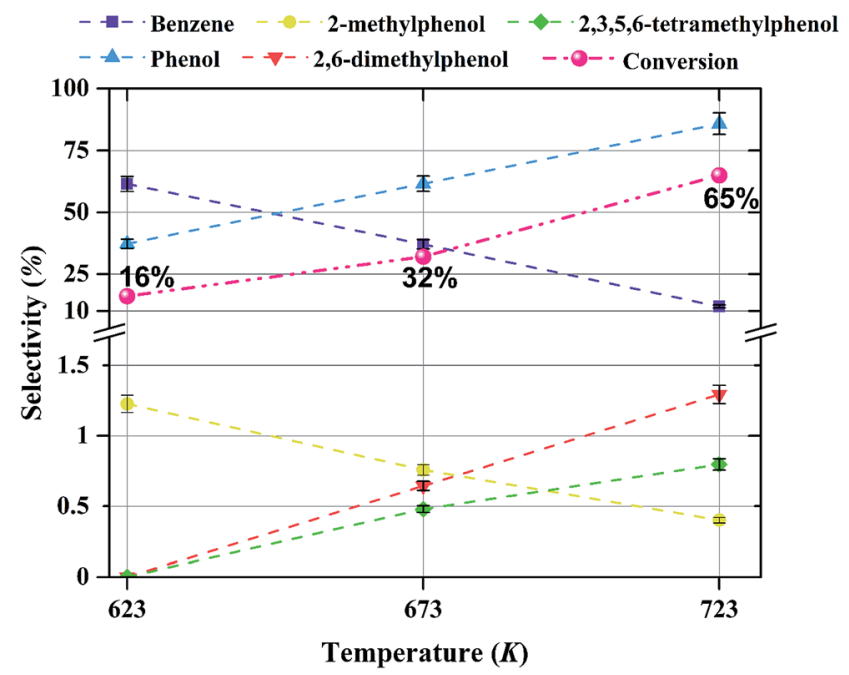

Fig. 11 Effect of temperature on selectivity for the formation of various products in anisole upgrading in the presence of $\mathrm{H}_{2}$ catalyzed by Mo/CNTs at 8 bar, with WHSV $=6.0$ ( $\mathrm{g}$ of anisole per $\mathrm{g}$ of catalyst per h); the catalyst molybdenum loading was $30 \mathrm{wt} \%$. The conversions are shown next to each point. 


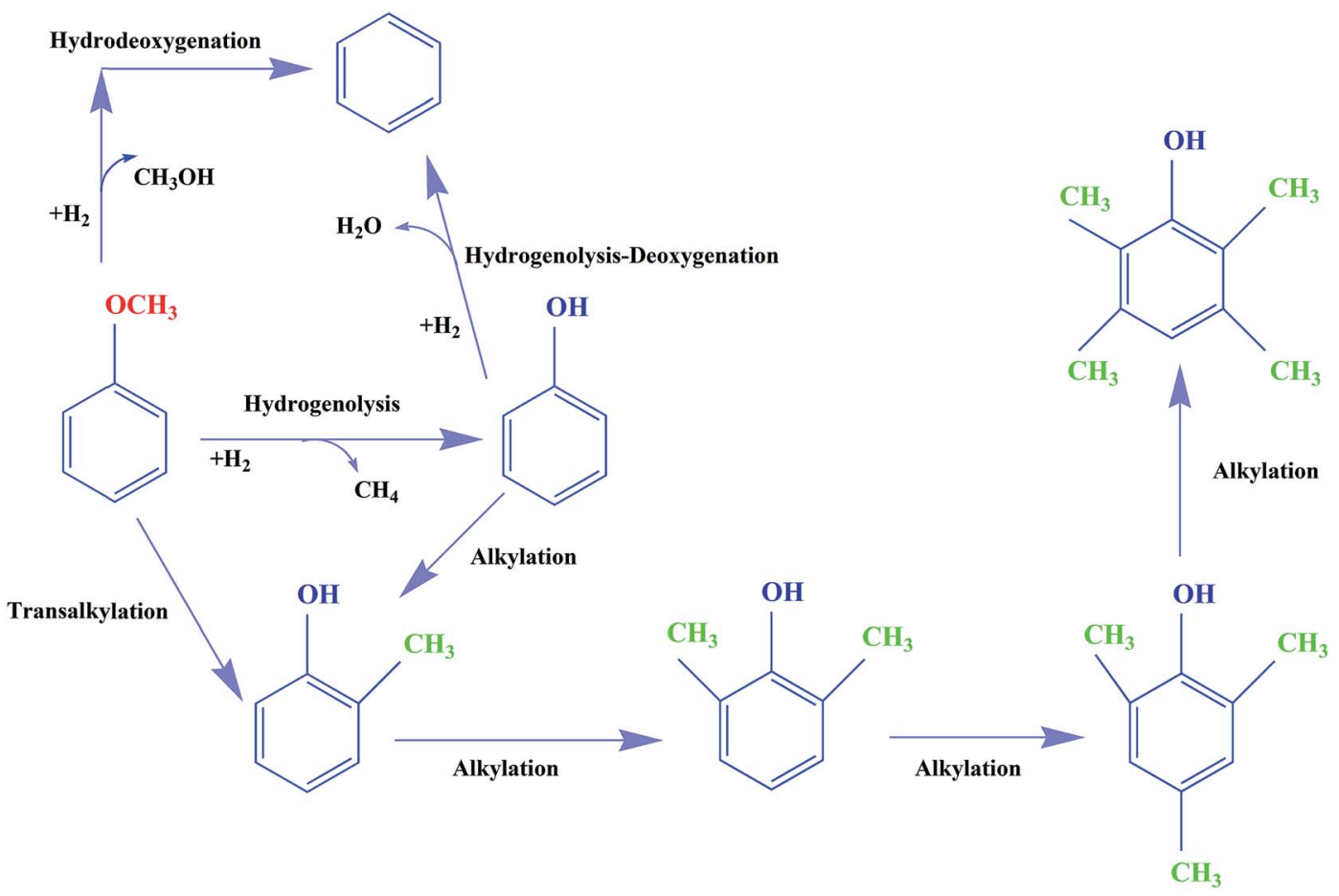

Fig. 12 Approximate, qualitative reaction network for the conversion of anisole in the presence of $\mathrm{H}_{2}$ catalyzed by Mo/CNTs at $623-723 \mathrm{~K}, 8$ bar, and WHSV $=6.0$ (g of anisole per $g$ of catalyst per $\mathrm{h}$ ).

Table 4 Anisole conversion as a function of catalyst mass at WHSV = 6 ( $\mathrm{g}$ of anisole per $\mathrm{g}$ of catalyst per $\mathrm{h}$ )

\begin{tabular}{lll}
\hline $\begin{array}{l}\text { Anisole flow } \\
\text { rate }\left(\mathrm{mL} \mathrm{min}^{-1}\right)\end{array}$ & $\begin{array}{l}\text { Mass of catalyst } \\
(\mathrm{g})\end{array}$ & $\begin{array}{l}\text { Anisole conversion } \\
(\%)\end{array}$ \\
\hline 0.03 & 0.3 & 44.5 \\
0.06 & 0.6 & 45.1 \\
0.1 & 1 & 44.2 \\
0.15 & 1.5 & 43.8 \\
0.2 & 2 & 43.5 \\
\hline
\end{tabular}

as well as on their outer surfaces. These catalytic species confined within the nanotubes would be expected to interact strongly with them, suggesting that they might be resistant to sintering and thus contribute to relatively long catalyst lifetimes; we posit that this suggestion is worthy of investigation. Encapsulation of the catalytic species within the narrow nanotubes might also affect their electronic properties and thereby their catalytic properties, and we suggest that this point is also worthy of investigation.

On the other hand, these encapsulated particles would be expected to block the small pores and thereby lead to small micro-effectiveness factors, such that the catalyst utilization might be markedly less than that in comparable catalysts on mesoporous supports. These issues remain to be resolved. A comparison of the activities of the catalysts reported here with those of other molybdenum-containing hydroprocessing catalysts leads to the inferences that Mo/CNT catalysts offer attractive activities and HDO selectivities..$^{\mathbf{3 4 4 5}}$

\section{Conclusions}

Mo/CNT catalysts were evaluated for the catalytic hydroprocessing of anisole as a model compound representing lignin-derived bio-oils. The catalyst performance data indicate that benzene, phenol, 2-methylphenol, 2,6-dimethylphenol, and 2,3,5,6-tetramethylphenol are the main products of anisole conversion in the presence of $\mathrm{H}_{2}$. The important reaction classes are HDO and hydrogenolysis, accompanied by transalkylation and alkylation reactions. Higher temperatures favor the selectivity for hydrogenolysis reactions.

\section{References}

1 M. Saidi, F. Samimi, D. Karimipourfard, T. Nimmanwudipong, B. C. Gates and M. R. Rahimpour, Energy Environ. Sci., 2014, 7, 103-129.

2 W.-S. Lee, Z. Wang, R. J. Wu and A. Bhan, J. Catal., 2014, 319, 44-53.

3 E. Furimsky, J. Mikhlin, D. Jones, T. Adley and H. Baikowitz, Can. J. Chem. Eng., 1986, 64, 982-985.

4 S. T. Srinivas, A. K. Dalai and N. N. Bakhshi, Can. J. Chem. Eng., 2000, 78, 343-354.

5 P. J. De Wild, W. J. Huijgen and R. J. Gosselink, Biofuels, Bioprod. Biorefin., 2014, 8, 645-657.

6 A. Demirbaş, Energy Convers. Manage., 2001, 42, 1357-1378.

7 E. Furimsky, Appl. Catal., A, 2000, 199, 147-190.

8 R. Venderbosch and W. Prins, Biofuels, Bioprod. Biorefin., 2010, 4, 178-208.

9 S. Czernik and A. Bridgwater, Energy Fuels, 2004, 18, 590-598. 
10 A. Oasmaa and S. Czernik, Energy Fuels, 1999, 13, 914-921.

11 X. Zhang, T. Wang, L. Ma, Q. Zhang, Y. Yu and Q. Liu, Catal. Commun., 2013, 33, 15-19.

12 A. Gutierrez, R. Kaila, M. Honkela, R. Slioor and A. Krause, Catal. Today, 2009, 147, 239-246.

13 M. Á. González-Borja and D. E. Resasco, Energy Fuels, 2011, 25, 4155-4162.

14 M. Bykova, D. Y. Ermakov, V. Kaichev, O. Bulavchenko, A. Saraev, M. Y. Lebedev and V. Yakovlev, Appl. Catal., B, 2012, 113, 296-307.

15 O. Şenol, E.-M. Ryymin, T.-R. Viljava and A. Krause, J. Mol. Catal. A: Chem., 2007, 277, 107-112.

16 A. Bridgwater and M. Cottam, Energy Fuels, 1992, 6, 113-120.

17 T. Nimmanwudipong, R. C. Runnebaum, K. Tay, D. E. Block and B. C. Gates, Catal. Lett., 2011, 141, 1072-1078.

18 R. C. Runnebaum, R. J. Lobo-Lapidus, T. Nimmanwudipong, D. E. Block and B. C. Gates, Energy Fuels, 2011, 25, 47764785.

19 T. Nimmanwudipong, R. C. Runnebaum, D. E. Block and B. C. Gates, Catal. Lett., 2011, 141, 779-783.

20 M. Saidi, P. Rostami, M. R. Rahimpour, B. C. Gates and S. Raeissi, Energy Fuels, 2015, 29, 191-199.

21 M. Saidi, P. Rostami, M. R. Rahimpour, B. C. Gates and S. Raeissi, Energy Fuels, 2014, 29, 191-199.

22 M. Saidi, P. Rostami, H. R. Rahimpour, M. A. Roshanfekr Fallah, M. R. Rahimpour, B. C. Gates and S. Raeissi, Energy Fuels, 2015, 29, 4990-4997.

23 T. Nimmanwudipong, R. C. Runnebaum, D. E. Block and B. C. Gates, Energy Fuels, 2011, 25, 3417-3427.

24 W. Wang, Y. Yang, H. Luo, H. Peng and F. Wang, Ind. Eng. Chem. Res., 2011, 50, 10936-10942.

25 C. Loricera, B. Pawelec, A. Infantes-Molina, M. ÁlvarezGalván, R. Huirache-Acuna, R. Nava and J. Fierro, Catal. Today, 2011, 172, 103-110.

26 I. Ghampson, C. Sepúlveda, R. Garcia, B. Frederick, M. Wheeler, N. Escalona and W. DeSisto, Appl. Catal., A, 2012, 413, 78-84.
27 E.-M. Ryymin, M. L. Honkela, T.-R. Viljava and A. O. I. Krause, Appl. Catal., A, 2010, 389, 114-121.

28 V. M. Whiffen and K. J. Smith, Energy Fuels, 2010, 24, 47284737.

29 H. Shang, C. Liu, Y. Xu, J. Qiu and F. Wei, Fuel Process. Technol., 2007, 88, 117-123.

30 Y. Yan, J. Miao, Z. Yang, F.-X. Xiao, H. B. Yang, B. Liu and Y. Yang, Chem. Soc. Rev., 2015, 44, 3295-3346.

31 P. Azadi, R. Farnood and E. Meier, J. Phys. Chem. A, 2009, 114, 3962-3968.

32 C. Li, Z. Shao, M. Pang, C. T. Williams, X. Zhang and C. Liang, Ind. Eng. Chem. Res., 2012, 51, 4934-4941.

33 M. Trépanier, A. Tavasoli, S. Anahid and A. K. Dalai, Iran. J. Chem. Chem. Eng., 2011, 30, 37-47.

34 T. Prasomsri, M. Shetty, K. Murugappan and Y. RománLeshkov, Energy Environ. Sci., 2014, 7, 2660-2669.

35 E. Soghrati, M. Kazemeini, A. Rashidi and K. J. Jozani, J. Taiwan Inst. Chem. Eng., 2014, 45, 887-895.

36 R. Ding, Y. Wu, Y. Chen, J. Liang, J. Liu and M. Yang, Chem. Eng. Sci., 2015, 135, 517-525.

37 W. Chen, Z. Luo, C. Yu, Y. Yang, G. Li and J. Zhang, Fuel Process. Technol., 2014, 126, 420-428.

38 A. Fazil and R. Chetty, Electroanalysis, 2014, 26, 2380-2387.

39 A. Kim, S. Lim, D.-H. Peck, S.-K. Kim, B. Lee and D. Jung, Nanomaterials, 2012, 2, 206-216.

40 H. R. Rahimpour, M. Saidi, P. Rostami, B. C. Gates and M. R. Rahimpour, Int. J. Chem. Kinet., 2016, 48, 702-713.

41 M. Saidi, H. R. Rahimpour, B. Rahzani, P. Rostami, B. C. Gates and M. R. Rahimpour, Can. J. Chem. Eng., 2016, 94, 1524-1532.

42 R. Sharma and N. Bakhshi, Can. J. Chem. Eng., 1991, 69, 1071-1081.

43 A. Centeno, E. Laurent and B. Delmon, J. Catal., 1995, 154, 288-298.

44 V. M. Whiffen, K. J. Smith and S. K. Straus, Appl. Catal., A, 2012, 419, 111-125.

45 M. Huuska, Polyhedron, 1986, 5, 233-236. 